\title{
Steatocystoma multiplex is associated with the R94C mutation in the KRT17 gene
}

\author{
QIAO LIU, WEIWEI WU, JIEJIE LU, PING WANG and FENG QIAO \\ Department of Dermatology, Hainan Provincial Hospital of Skin Disease, Haikou, Hainan 570206, P.R. China
}

Received September 8, 2014; Accepted June 9, 2015

DOI: $10.3892 / \mathrm{mmr} .2015 .4063$

\begin{abstract}
Steatocystoma multiplex (SM) is an uncommon disorder, characterized by numerous skin-colored subcutaneous cysts. A number of SM pedigrees have been identified with mutations in the keratin 17 (KRT17) gene. The present study examined a four-generation Chinese pedigree with an autosomal dominant mode of inheritance and examined its genetic basis. A review of the literature on KRT17 gene mutations in the SM pedigree was also performed to investigate the KRT17 gene mutation and genotype-phenotype correlation. Exon 1 of the KRT17 gene was amplified using polymerase chain reaction (PCR) from genomic DNA obtained, which was obtained from 25 family members in the selected Chinese pedigree and from 100 unrelated control individuals. The DNA was then subjected to automatic DNA sequencing. Genealogical investigations demonstrated an autosomal dominant pattern, and direct sequencing of the PCR product revealed a heterozygous mutation, c. $280 \mathrm{C} / \mathrm{T}$ (R94C), which was located in exon 1 of the KRT17 gene in all 10 affected family members. The mutation was not identified in the 15 unaffected family members or in the 100 unrelated control individuals. Therefore, the present study identified a causative mutation in the KRT17 gene in a large Chinese SM pedigree, exhibiting autosomal dominance. A review of the literature suggested that, in addition to the mutation factor, other modifying factors contribute to the phenotype of familial SM.
\end{abstract}

\section{Introduction}

Steatocystoma multiplex (SM; OMIM184500) is an uncommon disorder, which is characterized by numerous skin-colored subcutaneous cysts that originate from the pilosebaceous duct. Although a number of sporadic cases have been reported, SM is considered to be an autosomal

Correspondence to: Dr Weiwei Wu, Department of Dermatology, Hainan Provincial Hospital of Skin Disease, 49 South Longkun Road, Longkun, Haikou, Hainan 570206, P.R. China

E-mail: vigorwu@bjmu.edu.cn

Key words: steatocystoma multiplex, mutation, keratin 17 gene dominant disorder. Certain SM pedigrees have been identified with mutations in the keratin 17 (KRT17) gene, which have also been reported in patients with pachyonychia congenital type 2 (1). These mutations are highly conserved at the beginning sequence of helix 1A in the KRT17 gene, at which any substitution or deletion may lead to a distortion of the $\alpha$-helical structure at the beginning of the 1A domain (2). Mutations in this location are considered to have a significant effect on the assembly and/or integrity of the keratin cytoskeleton in cells (3). The tissues affected include the outer root sheath of the hair follicle, sebaceous glands, nail beds and other appendages (4), which explain the phenotypes of nail dystrophy and steatocystoma multiplex that are observed in patients with pachyonychia congenital type $2(3,5)$.

The present study investigated a Chinese four-generation autosomal dominant SM pedigree in order to identify the causative mutation by means of polymerase chain reaction (PCR) analysis and DNA sequencing. In addition, a literature review of KRT17 gene mutations in SM pedigrees was performed to investigate the KRT17 gene mutation and the genotype-phenotype correlation.

\section{Patients and methods}

Pedigree analysis. A four-generation Chinese SM pedigree with an autosomal dominant mode of inheritance was examined. The genealogical tree of this SM pedigree is shown in Fig. 1. The proband (III-13) was a 26-year-old male of Chinese Han-nationality, with the symptom of a gradual appearance of multiple skin-colored nodules on his whole body for $>20$ years. The lesions gradually developed in size and number at infancy, and became severe and obvious during puberty. The lesions were asymptomatic, however, were of cosmetic concern. When punctured, the cysts discharged yellowish, oily material and healed with a scar. The proband was in good general health and his routine laboratory investigations were within normal limits. On physical examination, multiple, skin-colored, firm, globoid nodules, measuring between 2 and $30 \mathrm{~mm}$ in diameter on the face, neck, chest, abdomen, arms and legs of the proband were identified (Fig. 2). The nail, palmoplantar areas, mouth, tongue and teeth were all normal. Histological examination of these lesions revealed that the cyst wall was composed of several layers of epithelial cells, accompanied by sebaceous gland lobules (Fig. 3). On the basis of these findings, the 
Family 1

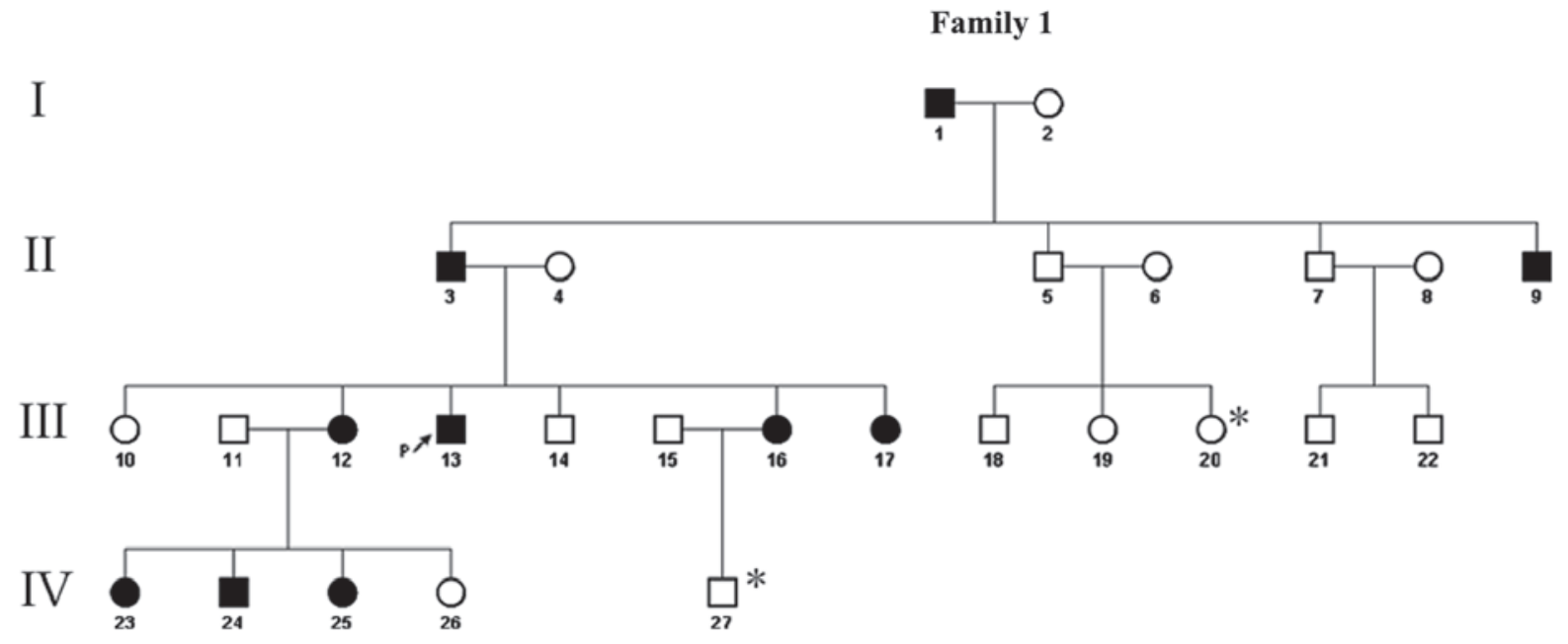

Figure 1. Four generation pedigree (I-IV) of the family comprising a number of individuals affected with SM. The squares indicate male family members and the circles indicate female family members. Black symbols indicate individuals exhibiting symptoms of SM, whereas white symbols indicate healthy, unaffected individuals. The proband (III-13) in the present study is indicated by an arrow. * indicates individuals from whom DNA was not obtained. SM, steatocystoma multiplex.

diagnosis of SM was made. Another nine affected members of his family reported a similar history, namely, his grandfather (I-1), father (II-3), uncle (II-9), three sisters (III-12,16,17), two nieces and one nephew (IV-23,24,25). None of these affected individuals exhibited any nail changes or any other skin, hair or mucosal abnormalities. The conditions of the patients varied and the condition of the female patients were comparatively milder in this family. The remaining members of this family had no history of SM.

Mutation analysis. Ethical approval was obtained from the ethics committee of Hainan Provincial Hospital of Skin Disease (Haikou, China) and written informed consent was also obtained. The genomic DNA was extracted from peripheral blood samples of 25 individuals within the family (10 affected and 15 unaffected family members) using a QIAamp blood-tissue kit (Qiagen, Hilden, Germany), according to the manufacturer's instructions. The exon 1 coding sequence of KRT17 (GenBank Entry: NM_000422) was amplified by polymerase chain reaction (PCR) using primer pairs designed with Primer3 (http://frodo.wi.mit. edu/primer3). The primer sequences were as follows: Forward 5'-ATGGAAACAGAGGAGCA-3' and reverse 5'-CCTGACTCAGCTTGCTGT-3'. The DNA template (100 ng) was mixed in a solution containing $1 \mathrm{X}$ PCR buffer, consisting of $100 \mathrm{mM}$ Tris- $\mathrm{HCl}(\mathrm{pH} \mathrm{8.3)}$ and $500 \mathrm{mM} \mathrm{KCl}$, $1.5 \mathrm{mM} \mathrm{MgCl}_{2}, 50 \mu \mathrm{M}$ dNTPs, 10 pmol of each primer, and 2.5 units of Taq DNA polymerase (Promega Corporation, Madison, WI, USA), in a final reaction volume of $30 \mu 1$. Amplification was performed in an initial denaturation at $95^{\circ} \mathrm{C}$ for $1 \mathrm{~min}$, followed by 35 cycles of denaturing at $95^{\circ} \mathrm{C}$ for $40 \mathrm{sec}$, annealing at $58^{\circ} \mathrm{C}$ for $40 \mathrm{sec}$ and extension at $72^{\circ} \mathrm{C}$ for $1 \mathrm{~min}$, with a final extension at $72^{\circ} \mathrm{C}$ for $3 \mathrm{~min}$. This resulted in a $830 \mathrm{bp}$ fragment with the use of Eppendorf Mastercycler Gradient PCR (Eppendorf, Hamburg, Germany). The PCR samples contained 5\% dimethyl sulfoxide to amplify the two fragments. The PCR products were purified using a Promega Wizard ${ }^{\circledR}$ SV 96 PCR Clean-up kit (Promega
Corporation), according to the manufacturer's instructions, eluted in $100 \mu 1 \mathrm{H}_{2} \mathrm{O}$ and directly sequenced using an ABI Prism 377 DNA sequencer (Applied Biosystems Life Technologies, Foster City, CA, USA). The mutation was confirmed by performing identical PCR and sequencing in 100 unrelated control individuals. Geneious version R8 software (Biomatters, Ltd., Auckland, New Zealand) was used to compare sequences.

Literature review. A literature review of KRT17 gene mutations in SM pedigrees was performed through searches of PubMed (http://www.ncbi.nlm.nih.gov/pubmed/), Ovid Medline (http://ovidsp.tx.ovid.com/sp-3.16.0a/ovidweb.cgi), EMBASE databases (www.embase.com) and China National Knowledge Infrastructure (http://www.cnki.net/). To the best of our knowledge, only seven types of KRT17 gene mutation in nine SM pedigrees have been reported in the literature $(2,3,5-17)$ (Table I).

\section{Results}

Identification of the large SM pedigree with autosomal dominant inheritance. Starting from the aforementioned proband, a four-generation pedigree was constructed through extensive genealogical investigation (Fig. 1). A total of 10 (five male and five female) of the 27 family members exhibited similar clinical manifestations. The availability of the phenotypic data led to the establishment of a mode of autosomal dominant inheritance in this large pedigree.

Identification of the causative gene using PCR and DNA sequencing. By direct sequencing of the KRT17 genomic PCR products, a heterozygous mutation (c. $280 \mathrm{C}>\mathrm{T}$ ) was identified in exon 1 of the KRT17 gene in all 10 affected family members, which causes an arginine to cysteine amino acid substitution at codon 94 (R94C). No such mutation was identified in any of the 15 unaffected family members or in the 100 unrelated control individuals (Fig. 4). 
Table I. Synopsis of KRT17 mutations in SM pedigrees in Chinese non-Chinese populations from a review of previous studies.

\begin{tabular}{|c|c|c|c|c|c|}
\hline Domain & Mutation & Phenotype & Heredity & Population & Reference \\
\hline V1 & $\mathrm{S} 24 \mathrm{~L} 71 \mathrm{C}>\mathrm{T}$ & SM & Familial & Chinese & (6) \\
\hline $1 \mathrm{~A}$ & N92H $274 \mathrm{~A}>\mathrm{C}$ & $\mathrm{SM}$ & Familial & & (7) \\
\hline $1 \mathrm{~A}$ & N92S 275A>G & $\begin{array}{l}\mathrm{SM} \\
\mathrm{PC}-2\end{array}$ & $\begin{array}{l}\text { Familial } \\
\text { Familial } \\
\text { Familial } \\
\text { Familial } \\
\text { Familial \& sporadic } \\
\text { Familial } \\
\text { Familial } \\
\text { Familial } \\
\text { Familial }\end{array}$ & Chinese & $\begin{array}{l}(8) \\
(2) \\
(3) \\
(5) \\
(7) \\
(9) \\
(10) \\
(11) \\
(12)\end{array}$ \\
\hline $1 \mathrm{~A}$ & $\begin{array}{l}\text { R94H } 281 \\
\text { G>A }\end{array}$ & $\begin{array}{l}\text { SM } \\
\text { SM } \\
\text { PC-2 }\end{array}$ & $\begin{array}{l}\text { Familial } \\
\text { Familial } \\
\text { Sporadic }\end{array}$ & Chinese & $\begin{array}{r}(7) \\
(8) \\
(13)\end{array}$ \\
\hline $1 \mathrm{~A}$ & $\begin{array}{l}\text { R94C } 280 \\
\text { C>T }\end{array}$ & $\begin{array}{l}\text { SM } \\
\text { SM } \\
\text { PC-2 }\end{array}$ & $\begin{array}{l}\text { Familial } \\
\text { Familial } \\
\text { Familial } \\
\text { Familial }\end{array}$ & Chinese & $\begin{array}{r}(14) \\
(15) \\
(3) \\
(12)\end{array}$ \\
\hline $1 \mathrm{~A}$ & R94G 280C $>$ G & SM & Familial & Chinese & (16) \\
\hline $2 B$ & L371P 1112T >C & $\mathrm{SM}$ & Familial & & $(17)$ \\
\hline
\end{tabular}

SM, steatocystoma multiplex; PC-2, pachyonychia congenital type 2 .

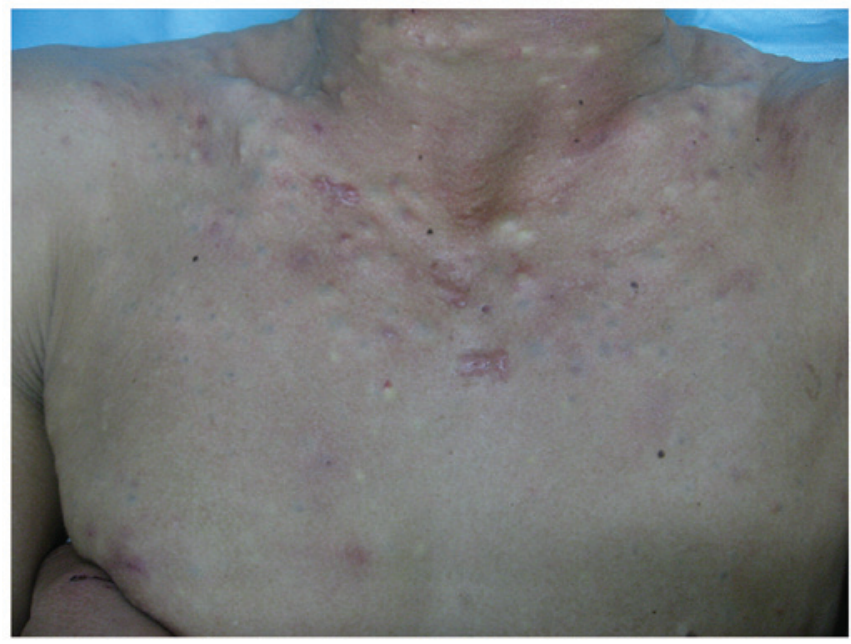

Figure 2. Steatocystoma multiplex lesions located on the neck and chest of the proband.

\section{Discussion}

The present study successfully identified the heterozygous mutation, c.280C >T (R94C) in exon 1 of the KRT17 gene as the cause of SM in the large, four-generation Chinese pedigree examined, and was revealed to be an autosomal dominant form.

By reviewing the previous literature $(2,3,5-17)$, it was revealed that seven mutations have been previously reported

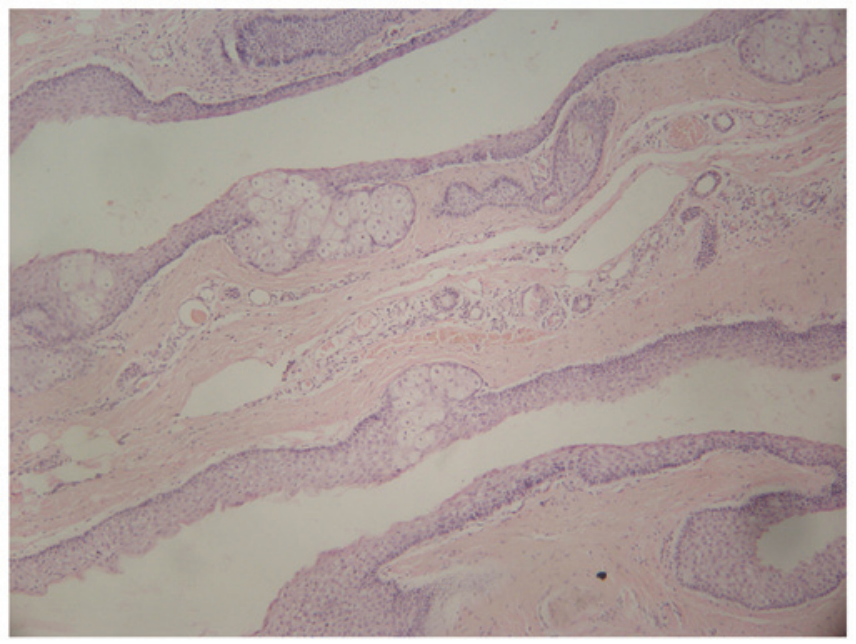

Figure 3. Hematoxylin and eosin stained histological section of a steatoma from the proband individual diagnosed with steatocystoma multiplex. A steatocystoma with sebaceous gland lobules in the cyst wall are present (magnification, $\mathrm{x} 40$ ).

in nine families with SM (Table I). These independent findings provided support for the involvement of the KRT17 gene in SM. A total of three of seven previously reported mutations, N92S, R94H and R94C, were associated with SM and PC-2, while the other four, S24L, N92H, L371P and R94G, were only associated with SM. S24L, N92S, R94H, R94C and R94G were reported in seven Chinese families with SM, 
A
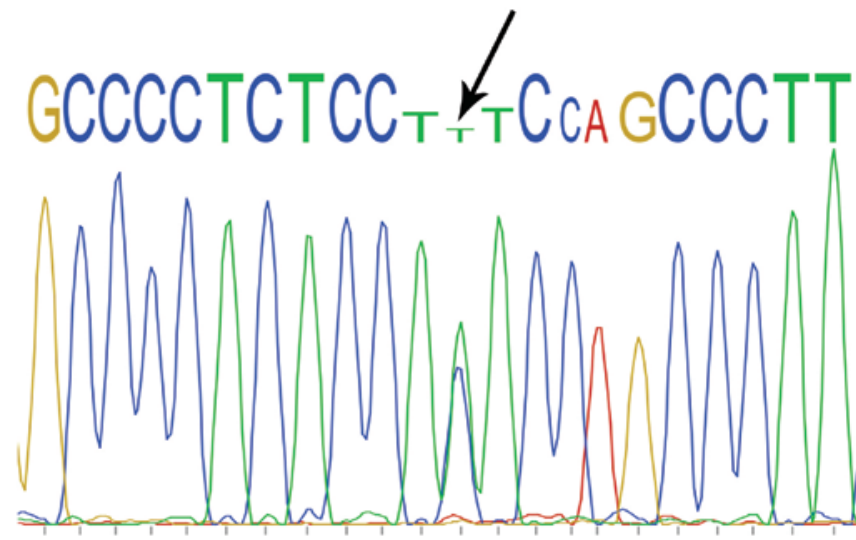

B
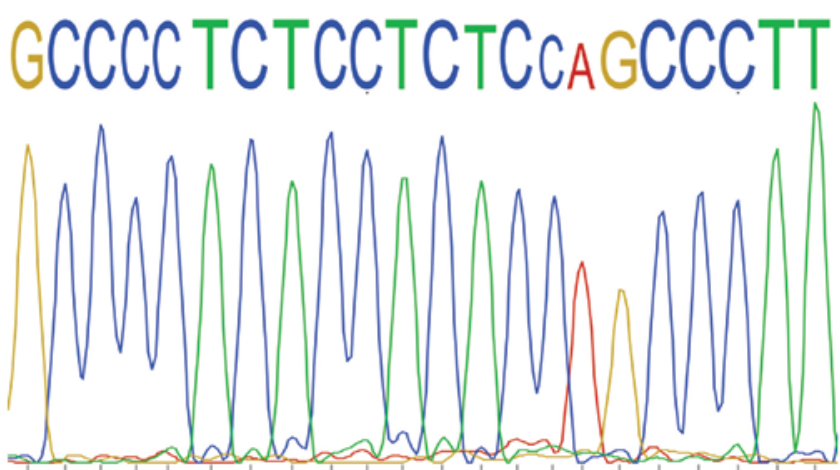

Figure 4. DNA sequence electrophoretogram of the DNA obtained from the proband (III-13) and the proband's mother (II-4). (A) DNA sequence electrophoretogram of the heterozygous mutation R94C (c.280C >T; GenBank entry: NM_000422) of KRT17 in the proband (indicated by the arrow). (B) No equivalent mutation was detected in the proband's mother.

and the R94C mutation has been detected previously in two families with SM and two families with PC-2 $(3,12,14,15)$, which was the second time that SM was observed in a Chinese family. The majority of mutations in familial SM have been reported within the highly conserved helix boundary domains at the end of the $\alpha$-helical rod domain of keratin (7,8,14-16).

According to the data obtained in previous studies, presented in Table I, a number of different mutations may lead to the identical clinical phenotype in SM, while the same mutations may cause different phenotypic variations in patients with SM or PC-2. Previous studies indicated variable onset ages of subcutaneous cysts in different SM pedigrees or SM family members. For example, with the R94C mutation, the onset of sebaceous cysts occurred in the same year as birth in certain individuals, however, no sebaceous cysts occurred until the second decade in other individuals $(14,15)$. This finding suggests that the genotype-phenotype correlation of SM may be determined, not only by the site and type of the KRT17 gene mutation, but also by other modifying factors. According to previous studies, androgenic stimulation and environmental factors have been suggested as the possible reasons $(2,3,18)$. In the pedigree examined in the present study, the early onset of clinical manifestations, aggravation during puberty, variable severity of different patients and milder symptoms in female family members appeared to support the above-mentioned hypothesis that there are other modifying factors contributing to the phenotype of familial SM.
In conclusion, using PCR and DNA sequencing, the present study identified a causative mutation, c. $280 \mathrm{C}>\mathrm{T}$ (R94C), in the KRT17 gene in a large Chinese SM pedigree with an autosomal dominant form. A review of the findings of previous studies suggested that, with the exception of the mutation factor, other modifying factors contribute to the phenotype of familial SM. This observation may assist in elucidating the molecular consequences of the KRT17 mutation in familial SM and may offer further insight into the correlation between KRT17 gene mutations and genotype-phenotype correlation.

\section{Acknowledgements}

The authors would like to thank the family members recruited for their participation in the present study. The authors would also like to thank Professor Yong Yang and Dr Zhimiao Lin (Department of Dermatology, Peking University First Hospital, Beijing, China) for assistance in DNA synthesis and sequencing.

\section{References}

1. McLean WH, Rugg EL, Lunny DP, Morley SM, Lane EB, Swensson O, Dopping-Hepenstal PJ, Griffiths WA, Eady RA and Higgins C: Keratin 16 and keratin 17 mutations cause pachyonychia congenita. Nat Genet 9: 273-278, 1995.

2. Feng YG, Xiao SX, Ren XR, Wang WQ, Liu A and Pan M: Keratin 17 mutation in pachyonychia congenita type 2 with early onset sebaceous cysts. Br J Dermatol 148: 452-455, 2003. 
3. Covello SP, Smith FJ, Sillevis Smitt JH, Paller AS, Munro CS, Jonkman MF, Uitto J and McLean WH: Keratin 17 mutations cause either steatocystoma multiplex or pachyonychia congenita type 2. Br J Dermatol 139: 475-480, 1998.

4. Troyanovsky SM, Leube RE and Franke WW: Characterization of the human gene encoding cytokeratin 17 and its expression pattern. Eur J Cell Biol 59: 127-137, 1992.

5. Smith FJ, Liao H, Cassidy AJ, Stewart A, Hamill KJ, Wood P, Joval I, van Steensel MA, Björck E, Callif-Daley F: The genetic basis of pachyonychia congenita. J Investig Dermatol Symp Proc 10: 21-30, 2005

6. Ha WW, Wang J, Wang W, Fu HY, Tang HY, Tang XF, Zhu J, Yin XY, Yang S and Zhang XJ: A novel missense mutation of keratin 17 gene in a chinese family with steatocystoma multiplex. Ann Dermatol 25: 508-510, 2013.

7. Smith FJ, CordenLD, Rugg EL, Ratnavel R, Leigh IM, Moss C, Tidman MJ, Hohl D, Huber $M$ and KunkelerL: Missense mutations in keratin 17 cause either pachyonychia congenita type 2 or a phenotype resembling steatocystoma multiplex. J Invest Dematol 108: 220-223, 1997.

8. Wang JF, Lu WS, SunLD, Lv YM, Zhou FS, Fang QY, Tang HY, Cui Y, Yang S and Zhang XJ: Novel missense mutation of keratin in Chinese family with steatocystoma multiplex. J Eur Acad Dermatol Venereol 23: 723-724, 2009.

9. Fujimoto W, NakanishiG, Hirakawa S, Nakanishi T, Shimo T, Takigawa $\mathrm{M}$ and Arata J: Pachyonychia congenita type 2: Keratin 17 mutation in a Japanese case. J Am Acad Dermatol 38 1007-1009, 1998

10. Cogulu O, Onay H, Aykut A, Wilson NJ, Smith FJ, Dereli T and Ozkinay F: Pachyonychia congenita type 2, N92S mutation of keratin 17 gene: Clinical features, mutation analysis and pathological view. Eur J Pediatr 168: 1269-1272, 2008.
11. Wilson NJ, Leachman SA, Hansen CD, McMullan AC, MilstoneLM, Schwartz ME, McLean WH, Hull PR and Smith FJ: A large mutational study in pachyonychia congenita. J Invest Dematol 131: 1018-1024, 2011.

12. Wilson NJ, Pérez ML, Vahlquist A, Schwartz ME, Hansen CD, McLean WH and Smith FJ: Homozygous dominant missense mutation in keratin 17 leads to alopecia in addition to severe pachyonychia congenita. J Invest Dematol 132: 1921-1924, 2012.

13. Terrinoni A, Smith FJ, Didona B, et al: Novel and recurrent mutations in the genes encoding keratins K6a, K16 and K17 in 13 cases of pachyonychia congenita. J Invest Dematol 117: 1391-1396, 2001.

14. Wang X, Shi Y, Ye Y, Liu F, Jin W, Chen W, Wang M, HuL, ZhaoG and Kong X: Keratin 17 gene mutation in patients with steatocystoma multiplex. Zhonghua Yi Xue Za Zhi 81: 540-543, 2001 (In Chinese).

15. Kamra HT, Gadgil PA, Ovhal AG and Narkhede RR Steatocystoma multiplex-a rare genetic disorder: A case report and review of the literature. J Clin Diagn Res 7: 166-168, 2013.

16. Zang D, Zhou C, He M, Ma X and Zhang J: A novel mutation (p.Arg94Gly) of keratin 17 in a Chinese family with steatocystoma multiplex. Eur J Dermatol 21: 142-144, 2011.

17. Gass JK, Wilson NJ, Smith FJ, Lane EB, McLean WH, Rytina E, Salvary I and Burrows NP: Steatocystoma multiplex, oligodontia and partial persistent primary dentition associated with a novel keratin 17 mutation. Br J Dermatol 161: 1396-1398, 2009.

18. Irvine $\mathrm{AD}$ and McLean WH: Human keratin diseases: The increasing spectrum of disease and subtlety of the phenotype-genotype correlation. Br J Dermatol 140: 815-828, 1999. 